\title{
VARIAÇÃO E MUDANÇA LINGUÍSTICA: UMA ANÁLISE DA AMPLIAÇÃO SEMÂNTICA DE ESTRANGEIRISMOS NO PORTUGUÊS BRASILEIRO
}

\author{
VARIACIÓN Y CAMBIO LINGÜÍSTICO: UN ANÁLISIS DE LA AMPLIACIÓN SEMÁNTICA DE \\ PRÉSTAMOS EN PORTUGUÉS BRASILEÑO
VARIATION AND LINGUISTIC CHANGE: AN ANALYSIS OF SEMANTIC EXPANSION OF LOANWORDS IN BRAZILIAN PORTUGUESE

\begin{abstract}
Docente do IFSP / Campus São Paulo - Departamento de Humanidades/C
\end{abstract}
\begin{abstract}
RESUMO: O artigo trata do uso de estrangeirismos no Português do Brasil sob a perspectiva da Teoria da Variação e Mudança Linguística; objetiva explicitar processos de implementação de mudança linguística por meio do uso de palavras estrangeiras, contemplando sua ocorrência, em grafia original, com ampliação semântica. Baseia-se em pressupostos teóricos labovianos e da área de Lexicologia. Em sua metodologia, levanta termos estrangeiros com ampliação semântica presentes nas revistas Época, Isto É e Veja, discute os dados e argumenta sobre a mudança linguística. Conclui que ampliação semântica é uma das maneiras de se validar um estágio final de implementação de mudança linguística.
\end{abstract}

PALAVRAS-CHAVE: sociolinguística variacionista; mudança linguística; estrangeirismos.

RESUMEN: El artículo trata del uso de préstamos en el Portugués de Brasil desde la perspectiva de la Teoría de la Variación y Cambio Linguístico; tiene como objetivo explicitar procesos de implementación de cambio linguístico por medio del uso de palabras extranjeras, contemplando su ocurrencia, en grafía original, con ampliación semántica. Se basa en presupuestos teóricos labovianos y del area de Lexicología. En su metodología, levanta términos extranjeros con ampliación semántica presentes en las revistas Época, Isto É y Veja, discute los datos y argumenta sobre el cambio linguístico. Concluye que la ampliación semántica es una de las maneras de validarse una fase final de implementación de cambio linguístico.

PALABRAS CLAVES: variación sociolinguística; cambio linguístico; préstamos.

ABSTRACT: This article examines the use of loanwords in Brazilian Portuguese from the perspective of the Theory of Linguistic Variation and Change. It aims to make explicit implementation processes of language change through the use of foreign words, by contemplating their occurrences, under their original spelling, and with semantic expansion. It is based on Lexicology and labovian theoretical assumptions. Regarding its methodology, it raises foreign terms with semantic expansion present in Época, Veja and Isto $\hat{E}$ magazines. It discusses the data and argues about linguistic change. It also concludes that semantic expansion is one way to validate a final implementation stage of linguistic change.

KEYWORDS: variationist sociolinguistics; linguistic change; loanwords.

\section{INTRODUÇÃO}

Campos (1986, p. 35) afirma que “[...] o empréstimo linguístico enriquece a língua que o recebe sem tornar mais pobre a língua que o cede". Considerado isso, destacamos que o Português sempre acolheu palavras novas, não sendo uma questão de empobrecimento de nossa língua, mas sim, uma forma profícua de enriquecimento. Nessa perspectiva, salientamos que a circulação de palavras estrangeiras no Brasil vem contribuindo para a ampliação de nosso léxico, e mais, em muitos casos, como analisado neste artigo, ampliando semanticamente seus usos.

Tecnicamente, conforme Carvalho (2002, p. 44), “[...] o empréstimo constitui-se na fase de instalação e adaptação do termo. O termo pode ser rejeitado, adotado ou substituído”. Nosso objetivo, neste artigo, é

\footnotetext{
*Doutor em Língua Portuguesa/PUC-SP. Pós-Doutorado em Letras/Mackenzie-SP. Endereço eletrônico: flaviusvaladares@hotmail.com
} 
provar que a ampliação semântica de termos estrangeiros em grafia original contempla o que Carvalho assevera. Para tanto, utilizamos os dados coletados de nossa tese de Doutorado ${ }^{1}$.

Estrangeirismo, a rigor, é o emprego de elementos de outras línguas, seja em palavras, seja em radicais de palavras. Trata-se de um fenômeno constante no contato que, naturalmente, existe entre comunidades linguísticas. Um exemplo disso é o termo office-boy, que designa o funcionário de um escritório, normalmente, responsável por fazer, entre outras atividades, pequenos trabalhos em bancos (GARCEZ; ZILLES, 2001).

A expressão office-boy, originalmente da língua inglesa, aos poucos foi se acomodando ao Português do Brasil, incorporando novas designações semânticas. Atualmente, quando alguém se refere ao mesmo funcionário, via de regra, diz apenas boy, termo que já traz sua predicação registrada no Houaiss; Villar (2001, p. 477). A expressão foi aportuguesada, adquirindo elementos próprios do idioma no Brasil, mas com valor semântico diferente do original. O termo boy, na língua inglesa, predica o substantivo "menino", diferente do sentido empregado na língua em uso pelos brasileiros.

A partir disso, consideramos o que Biderman (2001) indica sobre os diferentes tipos de estrangeirismos que ocorrem na língua portuguesa: 1] Decalque — versão literal do lexema-modelo concretizado, tendo em vista que tais palavras são calcos literais da palavra estrangeira, por exemplo, retroalimentação, supermercado e cartão de crédito; 2] Adaptação da forma estrangeira à fonética e à ortografia brasileira, quando, em geral, o estrangeirismo já foi adotado há muito tempo pela nossa cultura, por exemplo, boicote (boy-cott), clube (club) e drinque (drink); e 3] Incorporação do vocábulo com a sua grafia original, por exemplo, hardware, check-up e best sellers.

Além disso, corroboramos o que Sandmann (1997) aponta acerca dos grupos de neologismos por empréstimos: lexical, semântico e estrutural. O lexical ocorre quando há incorporação de palavra estrangeira em sua forma original, seja no aspecto fonológico-ortográfico (pizza), ou no ortográfico (clip e grid); morfossintático (campus-campi); plenamente adaptado à língua portuguesa (blecaute e robe), ou em processo de adaptação (stand>estande). O semântico é a tradução ou substituição de morfemas, mantendo marcas da importação (hot dog $>$ cachorro quente). No caso do estrutural, é a importação de modelo não vernáculo, como determinante + determinado (videoconferência).

Conceitualmente, Valadares (2014, p. 111) indica que estrangeirismos são

[...] palavras, efetivamente, oriundas de outro sistema linguístico, tomadas por empréstimo para suprir alguma necessidade conceitual, de ordem tecnológica, ou para a expressão de elementos socioculturais, referentes às trocas de ordem linguístico-cultural entre comunidades falantes de idiomas diversos. (VALADARES, 2014, p. 111)

Nesse processo, observando a ampliação do léxico da língua que recebe e consagra o termo estrangeiro, Fiorin (2001, p. 116) afirma que “[...] o léxico de uma língua é constituído da totalidade das palavras que ela possui, consideradas do ponto de vista das invariantes semânticas, independentemente da função gramatical que exercem na oração".

Isso corrobora a ideia de que não é o aportuguesamento de uma palavra estrangeira que vai tornar seu uso mais ou menos efetivo, e sim, sua utilização pelos usuários. Entendemos, ainda, que o léxico é o resultado da história de um povo, de seus contatos e de suas relações. E mais, compreendemos que a ampliação semântica compõe tais relações por consagrar os usos, por meio de novos contextos de sentido.

\section{SOCIOLINGUÍSTICA: UMA VISÃO CONCEITUAL}

Alkmin (2001) assinala que o estabelecimento da Sociolinguística, em 1964, é precedido pela atuação de vários pesquisadores, que buscavam articular a linguagem com aspectos de ordem social e cultural. Destaca Hymes (1962) e Labov (1963), com a publicação de Hymes de um artigo que propõe um novo domínio de

\footnotetext{
${ }^{1}$ Os dados foram coletados, a partir da análise realizada na tese de VALADARES, Flavio Biasutti. Uso de estrangeirismos no Português Brasileiro: variação e mudança linguística. 190f. Tese (Doutorado em Língua Portuguesa) - Pontifícia Universidade Católica de São Paulo (PUC/SP), São Paulo/SP, 2014.
} 
pesquisa, a Etnografia da Fala, e o trabalho de Labov sobre a comunidade da ilha de Martha's Vineyard, em que sublinha o papel decisivo dos fatores sociais na explicação da variação linguística, isto é, da diversidade linguística observada.

Com isso, constatamos que, a partir dos estudos de Labov (1972), a variação passa a ser considerada como inerente, regular e, enquanto tal, passível de uma análise linguística sistemática. Lorengian-Penkal (2004) ratifica nossa visão:

Isso quer dizer os estudos de Labov não se situam à margem de uma linguística da língua, uma vez que ele considera que esta só tem sentido em um contexto social. Em outras palavras, diferentemente de Saussure e Chomsky, por exemplo, Labov quer buscar a estrutura heterogênea da língua enquanto falada por uma comunidade ou grupo social. Seu foco de interesse não são as formas categóricas da língua, mas as variantes - formas alternativas de se dizer a mesma, permitidas pela própria estrutura da língua e motivadas por condicionamentos externos; Labov quer mostrar a existência e o funcionamento de regularidades na variação, quer mostrar que esta é sistemática e previsível. (LORENGIAN-PENKAL, 2004, p. 70)

Entendemos que a Sociolinguística, como indicam Chambers (1995), Monteiro (2000), Mattos e Silva (2002), Camacho (2003; 2013), Mollica (2003) e Cezário e Votre (2008), trata de evidenciar a heterogeneidade inerente da linguagem, demonstrando que a variação é sistemática, regular e ordenada, além de estudar a língua em seu uso real, levando em consideração as relações entre a estrutura linguística e os aspectos sociais e culturais. Também, que a variação como um princípio geral e universal, é passível de ser descrita e analisada cientificamente.

Camacho (2013, p. 19) atesta que a Sociolinguística “[ [...] incrementou, nas últimas três décadas, uma nova compreensão da natureza ao mesmo tempo variável e mutável da linguagem". E acrescenta: "Ativou também o reconhecimento do caráter regular e sistemático da heterogeneidade mediante um conjunto de estudos empíricos, de natureza quantitativa com foco na língua em uso no contexto social”. Considerado isso, sobre o objeto de estudo da Sociolinguística, Peres (2006) confirma que

[...] se as relações sociais dentro de uma determinada comunidade não são simples, a língua refletirá essa complexidade e será, obviamente, heterogênea. Entretanto, essa heterogeneidade pode ser sistematizada, e um dos grandes méritos da Teoria da Variação foi demonstrar que a variação linguística, existente em todas as épocas, em todas as comunidades de fala e em todos os níveis do sistema linguístico - fonético, lexical, sintático e semântico -, ocorre de forma organizada e regular. Outra grande contribuição dessa corrente foi o desenvolvimento de técnicas que permitiram sistematizar essa variação. (PERES, 2006, p. 39)

Afirmamos, então, que Labov é, de fato, o primeiro linguista que evidencia cabalmente a variação linguística como ordenada, padronizada e sistemática, por meio de seus, hoje, clássicos estudos: 1963, com a investigação da centralização dos ditongos / ay / e / aw/ em Martha's Vineyard; 1966, com o estudo sobre o $/ r /$ pós-vocálico na cidade de Nova Iorque e, 1972, com o estudo sobre o desaparecimento da cópula no inglês falado por adolescentes negros do Harlem, em Nova Iorque.

Em uma perspectiva de abordagem histórica dos estudos sociolinguísticos, em um âmbito de desenvolvimento desde o seu surgimento, Eckert (2005) destaca que os estudos variacionistas podem ser agrupados em três ondas de estudos, não substitutivas nem sucessivas, mas que se configuram como modos distintos de pensar a variação, com práticas analíticas e metodológicas peculiares.

A primeira onda de estudos sociolinguísticos, de acordo com Eckert (2005), inicia-se com os estudos de Labov sobre a estratificação do inglês na cidade de Nova Iorque, cujos resultados foram replicados em uma série de estudos em comunidades urbanas que corroboraram um padrão regular de estratificação socioeconômica das variáveis, em que o uso das variantes não-padrão está inversamente relacionado ao status socioeconômico do falante.

Nesta fase, houve o estabelecimento, conforme Freitag, Martins e Tavares (2012), de uma base sólida para o estudo da variação, correlacionando as variáveis linguísticas e as categorias sociais primárias. Disso decorreu que os padrões regulares e sistemáticos de covariação social e linguística levantaram questões 
sobre relações sociais subjacentes às categorias sociais primárias, o que conduziu ao surgimento da segunda onda, caracterizado por estudos etnográficos de populações mais localmente definidas.

Os autores reiteram que a premissa dos estudos da primeira onda é, pois, que as variedades linguísticas carregam o status social de seus falantes e que sua metodologia "[...] é calcada na correlação entre as variáveis linguísticas e as categorias socioeconômicas em sentido amplo (cuja classificação se dá de forma estável, homogênea e padronizada de modo a permitir a replicação, como faixa etária, sexo, etnicidade, escolaridade)" (FREITAG; MARTINS; TAVARES, 2012, p. 920). Ressaltam, ainda, a importância da estratificação dos falantes em células sociais, da constituição de bancos de dados linguísticos, bem como de resultados quantitativos refinados.

Eckert (2005) postula que os estudos da segunda onda são também de natureza quantitativa; no entanto, foca a abordagem etnográfica, com categorias sociodemográficas mais abstratas, evidenciando o valor local do vernáculo. Nesse tipo de abordagem, o foco está nos conceitos de comunidades de fala e de identidade de grupo. A autora propõe que "[...] o ponto de vista de variação relacionado à filiação de grupos e categorias locais aproxima as correlações de classe da experiência concreta e ilustra o valor positivo tanto do vernáculo quanto da resistência a ele, dependendo da posição das redes particulares na política econômica." 2 (ECKERT, 2005, p. 10).

Freitag, Martins e Tavares (2012, p. 921) ilustram três exemplos fornecidos por Eckert (2005):

(1) o estudo de Labov sobre o inglês afroamericano (AAVE), cujos resultados apontam para o uso de traços vernaculares por adolescentes como indexadores do status entre o grupo de comunidade de prática;

(2) o estudo de Milroy (1980), que enfoca comunidades de classe operária e examina a relação entre engajamento local e uso do vernáculo, correlacionando o uso de variáveis vernaculares locais com a densidade e a multiplicidade da rede de relações sociais do falante; e

(3) o estudo da própria Eckert (2000) sobre o papel das categorias jokers e burnouts na indexação de classe socioeconômica em grupos adolescentes. (FREITAG; MARTINS; TAVARES, 2012, p. 921)

Salientamos que Eckert (2005), ao ratificar os estudos da segunda onda, indica que

[...] a segunda onda estabeleceu uma relação entre o panorama da primeira e dinâmicas locais e pode ser resumida da seguinte forma: estudos etnográficos das comunidades geograficamente definidas, as categorias locais com links para variáveis demográficas, como a indexação de categorias e de estilo localmente definidas como atos de filiação ${ }^{3}$. (ECKERT, 2005, p. 15)

Freitag, Martins e Tavares (2012, p. 922) explicitam que os estudos da terceira onda incorporam a dinamicidade da estrutura, ou seja, “[ …] como a estrutura se molda no cotidiano, com os condicionamentos sociais impostos e as relações de poder estabelecidas atuando sobre ela”. Citando Eckert (2005), afirmam que os estudos da terceira onda combinam os postulados dos estudos da primeira e da segunda, com uma mudança no foco: da comunidade de fala para a comunidade de prática, isto é, unindo o estilo aos outros itens pesquisados pela teoria.

Eckert (2005) estabelece que a terceira onda se desenvolveu mais recentemente, centrada na variação vista não como o reflexo do lugar social num ponto da escala, mas como um recurso para a construção de significado social. Os estudos nesta perspectiva, conforme Freitag, Martins e Tavares (2012), combinam a metodologia quantitativa, presente nas perspectivas anteriores, aos corpora constituídos de modo a contemplar a dimensão mais cotidiana (o que não é necessariamente captado pela entrevista sociolinguística), com observações participantes, por exemplo. Por fim, Eckert (2005, p. 31) postula que

\footnotetext{
2 The view of variation as indexing affiliation to local groups and categories brings the class correlations down closer to concrete experience, and illustrates the positive value of both the vernacular and resistance to the vernacular, depending on the place of the particular networks in the political economy (Tradução nossa).

${ }^{3}$ The second wave established a connection between the big picture of the first wave and local dynamics, and can be summed up as follows: Ethnographic studies of geographically defined communities, local categories as links to demographics, variables as indexing locally-defined categories and style as acts of affiliation (Tradução nossa). Ratificamos que Camacho (2013, p. 253) justifica o uso do termo "onda" na tradução de "wave" por considerar que isso reflete o caráter que Eckert (2005) quis imprimir aos três movimentos da Sociolinguística.
} 
“[...] o foco no significado social exige que comecemos a considerar não só as variáveis regionais e as mudanças em andamento, mas também as variáveis que parecem ser exploradas para a significação social, independente de suas origens ${ }^{4}$ ".

\section{PALAVRAS ESTRANGEIRAS: ANALISANDO AS AMPLIAÇÕES SEMÂNTICAS}

Labov (2008) mostrou que a mudança linguística não pode ser compreendida fora da vida social da comunidade em que ela se produz, uma vez que pressões sociais são exercidas constantemente sobre a língua, ou seja, a explicação da mudança linguística, em suas palavras, “[...] parece envolver três problemas distintos: a origem das variações linguísticas; a difusão e propagação das mudanças linguísticas; e a regularidade da mudança linguística.” (LABOV, 2008, p. 19)

Alves (2002) afirma que todas as línguas utilizam neologismos, visto que a criação neológica faz parte da história das línguas e constitui uma evidência inequívoca de vitalidade, essencial para suprir as necessidades dos falantes e as condições de comunicação do idioma. Nesse sentido, o empréstimo da palavra estrangeira ocorreria no momento em que objetos, conceitos e situações nomeados em língua estrangeira se transferem para outra cultura.

Nesse aspecto, é importante também considerarmos que Sandmann (1997) observa como um indício seguro de que o empréstimo está bem adaptado à língua de chegada quando há palavras dele derivadas, como empréstimos advindos da língua inglesa que possuem termos derivados: snob que derivou esnobar, por exemplo.

Assim, seguindo Silva e Scherre (1996), adotamos o princípio metodológico que norteia o trabalho do pesquisador variacionista, que deve ter como procedimento:

1) identificar os fenômenos linguísticos variáveis de uma dada língua; 2) inventariar suas variantes, definindo as variáveis dependentes; 3) levantar hipóteses que deem conta das tendências sistemáticas da variação linguística; 4) operacionalizar as hipóteses através de variáveis independentes ou grupos de fatores de natureza linguística e não linguística; 5) identificar, levantar e codificar os dados relevantes, submetê-los a tratamento estatístico adequado com a interpretação dos resultados obtidos à luz das hipóteses levantadas. (SILVA; SCHERRE, 1996, p. 39-40)

Nessas perspectivas, analisamos a ampliação semântica que se configura, a nosso ver, como um estágio final de implementação da mudança linguística. Em nossa coleta, consideramos os termos estrangeiros: boom, pizza, round, top, game, miss e show. Optamos por analisar apenas os casos de palavras estrangeiras dicionarizadas, para assegurar a cientificidade.

Boom - Rubrica: economia.

Alta súbita na cotação de valores (p.ex., títulos, ações) ou mercadorias

Ex.: o b. da bolsa de valores

2 Rubrica: economia.

expansão rápida e muito abrangente da atividade econômica

2.1 desenvolvimento acelerado de cidade ou distrito

3 Rubrica: marketing.

ação intensa e planejada para divulgação de serviços, produtos, ideias, doutrinas etc.; propaganda intensiva

4. A focus on social meaning requires that we begin with a view not just to regional variables and changes in progress, but to the variables that appear to be exploited for social meaning, whatever their origins (Tradução nossa). 
$4 \quad$ Rubrica: marketing.

crescimento muito rápido na comercialização ou aceitação de um determinado produto

4.1 Rubrica: marketing.

crescimento ou expansão súbita de movimento em favor de alguma candidatura (HOUAISS; VILLAR, 2001, p. 488)

No caso da palavra boom, a ocorrência de ampliação semântica apareceu em nossos dados, como a seguir:

[1] "A bolha de crédito e o boom imobiliário que acabaram levando ao colapso do Leĥman Brothers e à atual estagnação não teriam ocorrido.” (A BOLHA..., p. 142, 2011)

[Q] "Com o boom de exposições e festivais dedicados à arte digital, Wiedmann aponta que é cada vez mais necessário buscar um diferencial curatorial.” (COM O BOOM..., p. $95,2011)$

[3] "O tênis teve um boom com Gustavo Kuerten na década passada.” (O TÊNIS..., p. $104,2011)$

O exemplo [1] apresenta a palavra sob a rubrica da economia, com o sentido de "expansão rápida e muito abrangente da atividade econômica”, conforme o Houaiss; Villar. No exemplo [2], a rubrica de marketing, significando "ação intensa e planejada para divulgação de serviços, produtos, ideias, doutrinas etc.; propaganda intensiva". Para o exemplo [3], temos "crescimento muito rápido na comercialização ou aceitação de um determinado produto”, também sob a rubrica de marketing.

Constatamos que o termo boom não foi utilizado em sua rubrica originalmente importada, ligada à economia no sentido de "alta súbita na cotação de valores (p.ex., títulos, ações) ou mercadorias”, de acordo com Houaiss; Villar. Nesse sentido, podemos confirmar que houve ampliação semântica do termo estrangeiro, passando este a designar outros conceitos no Português Brasileiro.

No caso da palavra pizza, a ocorrência de ampliação semântica não apareceu em nossos dados, apesar de identificarmos em seu verbete essa possibilidade, como em "acabar em pizza" no sentido de "ficar sem punição”, frequentemente utilizado pela mídia brasileira em relação a casos políticos de corrupção que não recebem punição.

Pizza - acabar em pizza ou virar pizza. Derivação: sentido figurado. Regionalismo: Brasil. Uso: informal. Ficar sem punição (falta ou um crime) [por conluio, p. ex., de parlamentares]. Ex.: o trabalho daquela comissão de inquérito acabou em pizza. (HOUAISS; VILLAR, 2001, p. 2231)

No mesmo caso, identificamos a palavra round, cuja ocorrência de ampliação semântica não apareceu em nossos dados, mas que também traz em seu verbete essa possibilidade:

Round - 1 assalto, no pugilismo

Ex.: luta em dez r.

2 Derivação: sentido figurado.

etapa de uma negociação difícil; combate entre dois pontos de vista

Ex.: o próximo r. na negociação da dívida externa

3 Rubrica: música.

m.q. cânone circular (HOUAISS; VILLAR, 2001, p. 2478) 
Para a palavra top, a ocorrência de ampliação semântica apareceu em nossos dados da seguinte maneira:

[1] "A temporada no Brasil da top Bárbara Fialho tem sido das mais produtivas." (A TEMPORADA...., p. 90, 2011);

[2] "O custo de um show internacional de artista top oscila entre $\mathrm{R} \$ 5$ milhões e $\mathrm{R} \$ 15$ milhões” (O CUSTO..., p. 106, 2011); e

[3] "Pela ordem de 'ataque', o top Marlon Teixeira, o ator Carlos Machado e o galã da novela 'Fina Estampa', Carlos Casagrande.” (PELA ORDEM...., p. 69, 2011)

Top-Regionalismo: Brasil.

1 Rubrica: física de partículas elementares.

ver quark

2 Rubrica: televisão.

sinal breve us. para atrair a atenção dos ouvintes ou telespectadores para um instante preciso da transmissão (p. ex., o início de um programa)

3 Rubrica: vestuário.

espécie de blusa curta, sem mangas, que deixa à mostra os ombros

4 Rubrica: vestuário.

m.q. bustiê

(HOUAISS; VILLAR, 2001, p. 2734)

Nos itens [1], [2] e [3], a ampliação semântica ocorreu para caracterizar alto prestígio, em que o termo top foi utilizado como aposto [1] e [3] e como adjetivo [2]. Os 3 exemplos não têm, em seu verbete no dicionário, tal rubrica, o que caracteriza uma ampliação ainda não contemplada pelo Houaiss; Villar.

Isso denota que os termos estrangeiros, logo que são dicionarizados, costumeiramente assumem seu significado original na língua de empréstimo, para depois, conforme a aceitação e o uso, chegarem à possibilidade de ampliação semântica, como ocorre com os termos exemplificados. Nesse aspecto, frisamos que a ampliação semântica justifica nossa hipótese de implementação da variação e mudança linguística em estágio final, sem a necessidade de seu aportuguesamento, em razão de a variável estável, com uso frequente pela comunidade linguística, ter-se ampliado para outros sentidos e consequentes usos.

\section{Game}

1 em tênis, cada uma das subdivisões de um set vencida pelo jogador ou dupla que completa quatro pontos

2 em bridge, um dos dois escores parciais de 100 ou mais pontos, em valores de vazas contratadas e cumpridas, necessários para vencer um rubber (HOUAISS; VILLAR, 2001, p. 1423)

Game figurou, em nossa coleta, com o sentido de jogo digital, criado a partir do desenvolvimento de tecnologias nesse âmbito. Nesse ponto, destacamos que houve a ampliação semântica, uma vez que o dicionário Houaiss; Villar ainda traz a acepção ligada apenas ao esporte. Isso indica que essa ampliação semântica denota a variável estável - sentido de esporte - com a ampliação de sentido, o que configura, a 
nosso ver, que o termo estrangeiro foi absorvido pela comunidade linguística e encontra-se sedimentado no uso do Português do Brasil.

“Games” (GAMES, p. 107, 2011)

“[...] vide os primeiros games e programas de texto para computadores.” (VIDE..., p. $114,2011)$

"Um nerd provou ser um verdadeiro fã da série Mario, o game mais famoso e mais vendido no mundo." (UM NERD..., p. 26, 2011)

“Assassin'S Cred, de Oliver Bowden, é a adaptação da história por trás do game homônimo [...]” (ASSASSIN’S..., p. 143, 2011)

“A versão analógica para o game Angry birds envolve e diverte” (A VERSÃO..., p. 130, 2011)

"Games" (GAMES, p. 133, 2011)

"No intervalo entre uma apresentação e outra, fãs de rock podem testar seus conhecimentos musicais em divertidos games produzidos pelo site." (NO INTERVALO, p. 9, 2011)

“[...] o número de ameaças desenvolvidas para games chegou a 2,4 milhões só no primeiro semestre de $2011[\ldots]$ ” (O NÚMERO..., p. 46, 2011)

Miss

1 nos países de língua inglesa e internacionalmente, forma de tratamento formal que antecede o nome de uma mulher solteira

2 a primeira colocada num concurso que elege a jovem mais bonita de um lugar ou a que obteve a preferência da maioria dos julgadores, com relação a outras qualidades (simpatia, p.ex.)

Obs.: inicial maiúsc. quando intitulativo

Exs.: M. Bahia

M. Brasil

M. Simpatia

3 Derivação: por extensão de sentido.

moça muito bonita e vistosa

Ex.: a filha dele é uma miss

(HOUAISS; VILLAR, 2001, p. 1934)

No caso da palavra miss, não ocorreu em nossos dados um uso diferente da acepção de concurso; no entanto, o dicionário Houaiss; Villar registra uma extensão de sentido por derivação, atribuindo o sentido de "moça bonita e vistosa”, o que agregaria sentido ao originalmente colocado na $1^{\mathrm{a}}$ acepção do dicionário, configurando uma ampliação semântica que denota a estabilidade da variável. 


\section{Show}

1 espetáculo (musical, humorístico etc.) apresentado em teatro, televisão, rádio, casas noturnas ou mesmo ao ar livre

2 Rubrica: radiofonia, televisão.

programa de variedades, com a participação de vários artistas (ou mesmo de um só) e por vezes também do público

- dar um $s$.

Derivação: sentido figurado. Regionalismo: Brasil.

1 exibir-se de forma magistral; ter um desempenho brilhante na sua atividade

Ex.: a seleção brasileira deu um s.

2 fazer escândalo

Ex.: ao sentir-se agarrada, a moça deu um s.

- um $s$.

Regionalismo: Brasil. Uso: informal.

um espetáculo, uma beleza

Ex.: essa garota é um s.

(HOUAISS; VILLAR, 2001, p. 2565)

Para a palavra show, o dicionário Houaiss; Villar apresenta algumas acepções; todavia, em nossa coleta, a maioria dos usos foi relacionada à $1^{\mathrm{a}}$ acepção, com o sentido de espetáculo. Há, contudo, um caso em nossa coleta no qual a ampliação semântica para "fazer escândalo" ocorreu, comprovando que seu uso, de fato, comporta tal ampliação e ratifica a variação e mudança linguística nesta perspectiva, com a estabilidade da variável.

O MAGNATA russo da comunicação Alexander Lebedev, dono do jornal The Independent e de outras publicações no Reino Unido, deu show de selvageria em um programa de TV da Rússia. (O MAGNATA..., p. 17, 2011)

De outra forma, Berber Sardinha e Barbara (2005, p. 104), especificamente sobre a palavra marketing, observaram que seu uso é mais frequente na língua portuguesa do Brasil que na língua inglesa e salientam que o termo equivalente para marketing em português é mercadoria (conforme o Dicionário Aurélio), diferentemente do importe original. Os autores exemplificam com os seguintes trechos:

Cargos dentro de uma área de atuação profissional: gerente ( de marketing), diretor, diretora, consultor, assistente.

Tema de evento especializado: ciclo, quinzenal ("ciclo quinzenal Arena do Marketing"), palestrante, palestra. (BERBER SARDINHA; BARBARA, 2005, p. 105)

Além disso, postulam que "jogada de marketing”, por exemplo, parece carregar uma prosódia semântica negativa, indicada pelo léxico: "não passa de (uma simples) jogada de marketing/apenas uma jogada de marketing/envolvido numa jogada de marketing”. Também, indicam outras colocações semelhantes de marketing: "lance de marketing" e "golpe de marketing". (BERBER SARDINHA e BARBARA, 2005, p. 106) 


\section{CONCLUSÃO}

Para explicar a mudança, é preciso dizer o que aconteceu (fatos) e por quê (princípios), como observam Coan e Freitag (2010, p. 178). Em nosso corpus, está claro que as palavras com ampliação semântica já se encontram em um processo final de implementação de mudança linguística, com a adoção do termo estrangeiro sem seu aportuguesamento, ou seja, a variável estável é a palavra importada e permanece em grafia original.

No que se refere à ampliação semântica, entendemos que, ao existir uma ampliação de sentido para um termo estrangeiro, após sua permanência na língua e consequente inserção como variável estável, as análises caminharam para o entendimento de que a implementação cumpriu seu ciclo no uso pelos falantes, possibilitando tal ampliação, como é o caso dos termos estrangeiros boom, pizza, round, top, game, miss e show.

Desse modo, adotamos o que considera Weinreich, Labov e Herzog (2006, p. 126) a respeito da mudança linguística: “[...] nem toda variabilidade e heterogeneidade na estrutura linguística implica mudança; mas toda mudança implica variabilidade e heterogeneidade". Nesse sentido, nossos dados apontaram para casos que se enquadram neste conceito.

Assim, verificamos que a ampliação semântica é, de fato, indicativo bem consistente de que o termo estrangeiro já se encontra em estado final de implementação do processo de mudança linguística, uma vez que os usuários da língua não só o acolheram como também produziram novos sentidos, o que reflete cabalmente sua inserção no léxico da língua, como apresentado em nossos dados.

\section{REFERÊNCIAS}

ALKMIN, T. Sociolinguística - Parte I. In.: MUSSALIM, F.; BENTES, A. C. Introdução à linguística. São Paulo: Cortez, 2001. v. 1.

ALVES, I. M. Neologismo: criação lexical. São Paulo: Ática, 2002.

BERBER SARDINHA, T.; BARBARA, L. Frequência e uso de estrangeirismos ingleses no português do Brasil: Um estudo baseado em corpus. Revista Brasileira de Linguística Aplicada, v. 5, n. 1, 97-1 14, 2005.

BIDERMAN, M. T. C. Teoria linguística: teoria lexical e linguística computacional. São Paulo: Martins Fontes, 2001.

CAMACHO, R. G. O formal e o funcional na teoria variacionista. In: RONCARATI, C.; ABRAÇADO, J. (Org.). Português brasileiro: contato linguístico, heterogeneidade e história. Rio de Janeiro: 7Letras, 2003. p. $55-65$.

CAMACHO, R. G. Da Linguística formal à linguística social. São Paulo: Parábola, 2013.

CAMPOS, G. O que é tradução. São Paulo: Brasiliense, 1986.

CARVALHO, N. Empréstimos linguísticos. São Paulo: Ática, 2002.

CEZARIO, M. M.; VOTRE, S. Sociolinguística. In.: MARTELlOTA, M. E. (Org.). Manual de Linguística. São Paulo: Contexto, 2008. p. 141-155.

CHAMBERS, J. K. Sociolinguistic theory. Oxford, Cambridge: Blackwell, 1995.

COAN, M.; FREITAG, R. M. K. Sociolinguística variacionista: pressupostos teórico-metodológicos e propostas de ensino. Domínios da Linguagem, Uberlândia/MG, v. 4, n. 2, 2. sem.2010. p.173-194.

ECKERT, P. Variation, convention and social meaning. Paper presented at the Annual Meeting of the Linguistic Society of America. Oakland CA. jan. 7, 2005. 33p. 
FIORIN, J. L. (Org.) Introdução à linguística — objetos teóricos. São Paulo: Contexto, 2001. p. 7-10.

FREitaG, R. M. K.; MARTins, M. A.; TAVARES, M. A. Bancos de dados sociolinguísticos do português brasileiro e os estudos de terceira onda: potencialidades e limitações. Alfa, São Paulo, v. 56 (n.3): 917-944, 2012.

GARCEZ, P. de M.; ZILLES, A. S. M. Estrangeirismos: desejos e ameaças. In.: FARACO, C. A. (Org.) Estrangeirismos: guerras em torno da língua. São Paulo: Parábola, 2001. p. 15-36.

HOUAISS, A.; VILlAR, M. de S. Dicionário Houaiss da língua portuguesa. Rio de Janeiro: Objetiva, 2001.

LABOV, W. Padrões sociolinguísticos. Trad. Marcos Bagno, Maria Marta Pereira Scherre e Caroline Rodrigues Cardoso. São Paulo: Parábola Editorial, 2008.

LABOV, W. Principles of linguistic change. Oxford: Blackwell, 1994. v. 1

LOREGIAN-PENKAL, L. (Re)análise da referência de segunda pessoa na fala da região Sul. 2004, 261f. Tese (Doutorado em Linguística) - Programa de Pós-Graduação em Letras, Universidade Federal do Paraná, Curitiba, 2004.

MATTOS E SILVA, R. V. Variação, mudança e norma: movimentos no interior do português brasileiro. In: BAGNO, M. (Org.). Linguística da norma. São Paulo: Edições Loyola, 2002. p. 63-90.

MOLLICA, M. C. Fundamentação teórica: conceituação e delimitação. In: MOLLICA, M. C.; BRAGA, M. L. (Org.). Introdução à sociolinguística: o tratamento da variação. São Paulo: Contexto, 2003. p. 9-14.

MONTEIRO, J. L. Para compreender Labov. 2. ed. Petrópolis: Vozes, 2000.

PERES, E. P. O uso de você, ocê e cê em Belo Horizonte: um estudo em tempo aparente e em tempo real. 2006. 247f. Tese (Doutorado em Linguística) - Programa de Pós-Graduação em Letras, Universidade Federal de Minas Gerais, Belo Horizonte/MG, 2006.

SANDMANN, A. J. Morfologia lexical. São Paulo: Contexto, 1997.

SANTOS, A. S. dos. Dicionário de anglicismos e de palavras inglesas correntes em português. Rio de Janeiro: Elsevier, 2006.

SILVA, G. M. de O.; SCHERRE, M. M. P. (Org.). Padrões Sociolinguísticos - análises de fenômenos variáveis do português falado no Rio de Janeiro. Rio de Janeiro: Tempo Brasileiro, 1996.

VALADARES, F. B. Uso de estrangeirismos no Português Brasileiro: variação e mudança linguística. 2014. 190f. Tese (Doutorado em Língua Portuguesa) - Programa de Estudos Pós-Graduados em Língua Portuguesa, Pontifícia Universidade Católica de São Paulo (PUC/SP), São Paulo, 2014.

WEINREICH, U.; LABOV, W.; HERZOG, M. Fundamentos empíricos para uma teoria da mudança linguística. Trad. Marcos Bagno. São Paulo: Parábola Editorial, 2006.

\section{REFERÊNCIAS: PERIÓDICOS UTILIZADOS}

A BOLHA de crédito. Veja, São Paulo, n. 36, ed. 2233, p. 142, 07.set.2011.

A TEMPORADA no Brasil. Isto É, São Paulo, n. 2182, p. 90, 07.set.2011.

A VERSÃO analógica. Época, São Paulo, n. 697, p. 130, 26.set.2011.

ASSASSIN’S CRED. Época, São Paulo, n. 696, p. 143, 19.set.2011.

Forum linguistic., Florianópolis, v.11, n.4, p.403-414, out./dez.2014. 
COM O BOOM de exposições. Isto É, São Paulo, n. 2184, p. 95, 21. set.2011.

GAMES. Época, São Pauo, n. 695, p. 107, 12.set.2011.

GAMES. Época, São Pauo, n. 697, p. 133, 26.set.2011.

NO INTERVALO. Veja, São Paulo, ed. 2236, n. 39, p. 9, 28. set.2011.

O CUSTO de um show. Isto É, São Paulo, n. 2183, p. 106, 14.set.2011.

O MAGNATA russo. Época, São Paulo, n. 697, p. 17, 26. set.2011.

O NÚMERO de ameaças. Veja, São Paulo, ed. 2236, n. 39, p. 46, $28 . s e t .2011$.

O TÊNIS teve. Veja, São Paulo, n. 39, ed. 2236, p. 104, 28.set.2011.

PELA ORDEM de 'ataque'. Isto É, São Paulo, n. 2184, p. 69, 21. set.2011.

UM NERD provou. Época, São Paulo, n. 696, p. 26, 19.set.2011.

VIDE os primeiros games. Isto É, São Paulo, n. 2183, p. 114, 14.set.2011.

Recebido em 06/05/2015. Aprovado em 23/05/15. 